\title{
Flatulence, CTCAE
}

National Cancer Institute

\section{Source}

National Cancer Institute. Flatulence, CT CAE. NCI Thesaurus. Code C57807.

A disorder characterized by a discharge of excessive gas from the lower Gl tract. 